\title{
FAULT ANALYSIS ON NIGERIA 330kV TRANSMISSION SYSTEM USING ETAP
}

\author{
O. Oputa ${ }^{1, *}$ and T. C. Madueme ${ }^{2}$ \\ 1. Dept. of Electrical/Electronic Engr., Michael Okpara Univ. of Agriculture, Umuahia, Abia State, Nigeria.

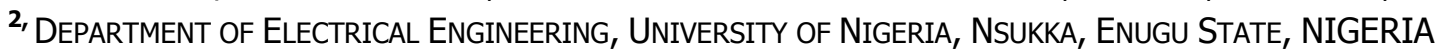 \\ Email addresses: ${ }^{1}$ connectositao@gmail.com ${ }^{2}$ theophilus.madueme@unn.edu.ng
}

\begin{abstract}
The 330kV transmission network is the back bone of the Nigeria power system as it connects all power plants and load centers in all parts of the country; hence its economic importance cannot be over emphasized. Fault occurrence in this network slows down economic and other sectors' activities; hence proper plan should be put in place to protect the system from the adverse effect of these faults when they occur. This paper has presented the nature of the system when these faults occur in three Buses (4, 16 and 23 corresponding to Niger, Oshogbo and Alaoji respectively) by simulation in ETAP. The results also show that double line to ground, LLG (between line "a" and "b") fault at bus 23 produces a $0.0 \mathrm{kV}$ in the 2 affected lines but a high voltage of 112\% of rated voltage at line ' $c$ ' in the faulty bus 23. This same LLG fault at bus 16 produces similar result but a higher line ' $c$ ' voltage of $131 \%$ of rated line voltage in the faulty bus 16. LL faults always result reduction in voltage of the two lines under fault. In bus 23 , the line voltages of the affected lines were $49.32 \%$ of the rated line voltage. With this analysis, the behavior of the network when different faults occur at different locations has been known by the protection engineers, protecting the network can be a lot cheaper and effective making the system more reliable, effective and profitable.
\end{abstract}

Keywords: Fault; Analysis; Transmission; System; ETAP.

\section{INTRODUCTION}

A fault in transmission systems is an unpermitted deviation of at least one characteristic property (or feature) of the system from the acceptable, usual, standard condition. When these faults occur, outages are experienced in the affected areas leading to nonprofitability in the side of the service providers and reduced productivity to the costumers. These faults causes abnormal condition as well as a reduction in the basic insulation strength between

(i) Phase conductors or

(ii) Phase conductor and earth, or any earth screens surrounding the conductors.

When these faults occurs in any power system network, the consequences include

(i). A sharp reduction in line voltage in most parts of the system leading to system failure.

(ii). Electrical arc often accompanying a short circuit that damages other electrical apparatus. (iii). Overheating of lines and equipment in the system that can lead to damages.

(iv). Sharp reduction in voltage of healthy feeders connected to the faulty feeders if the faulty feeder is not quickly discriminated $[1,2,3]$.

The Nigeria $330 \mathrm{kV}$ transmission system is very much exposed to different types of faults ranging from balanced and unbalanced faults occurring at various stages of the system. This includes faults from the generation stations (occurring at alternators terminals, bus bars, etc.), the transmission substations (at transformer windings and terminals, synchronous condensers windings and terminals, bus bars, etc.) and the transmission lines. In Nigeria $330 \mathrm{kV}$ transmission system, the frequency of occurrence of these faults is highest at the power lines. This is because these lines pass through bushes, towns and villages. The towels or poles are liable to attack from collision with heavy duty vehicles

* Corresponding author, tel: + $234-803-540-0477$ 
or self-breaking due to ageing can break lines and cause line bridging or earth faults. The line cables are exposed to trees falling on them and breaking the lines thereby giving rise to faults occurrence. However, the effect of the fault occurrence is lowest at the power lines and more severed at the generation and substations; hence, our concentration in this paper shall be on such locations.

The Nigeria 330kV transmission system consist of 28 buses power system network with 9 power generating plants delivering power at this voltage level and number of transmission substation $[4,5]$ as shown in Figure 1.

In this study, the buses are identified and specified as shown in Table 1 . The power plant and the transmission lines are described in Tables 2 and 3 respectively.

The various power plants supplying power to this $330 \mathrm{kV}$ network and their capacity is given in the table 2. The various lines connecting the various buses in the network and their respective distances are as given in Table 3.

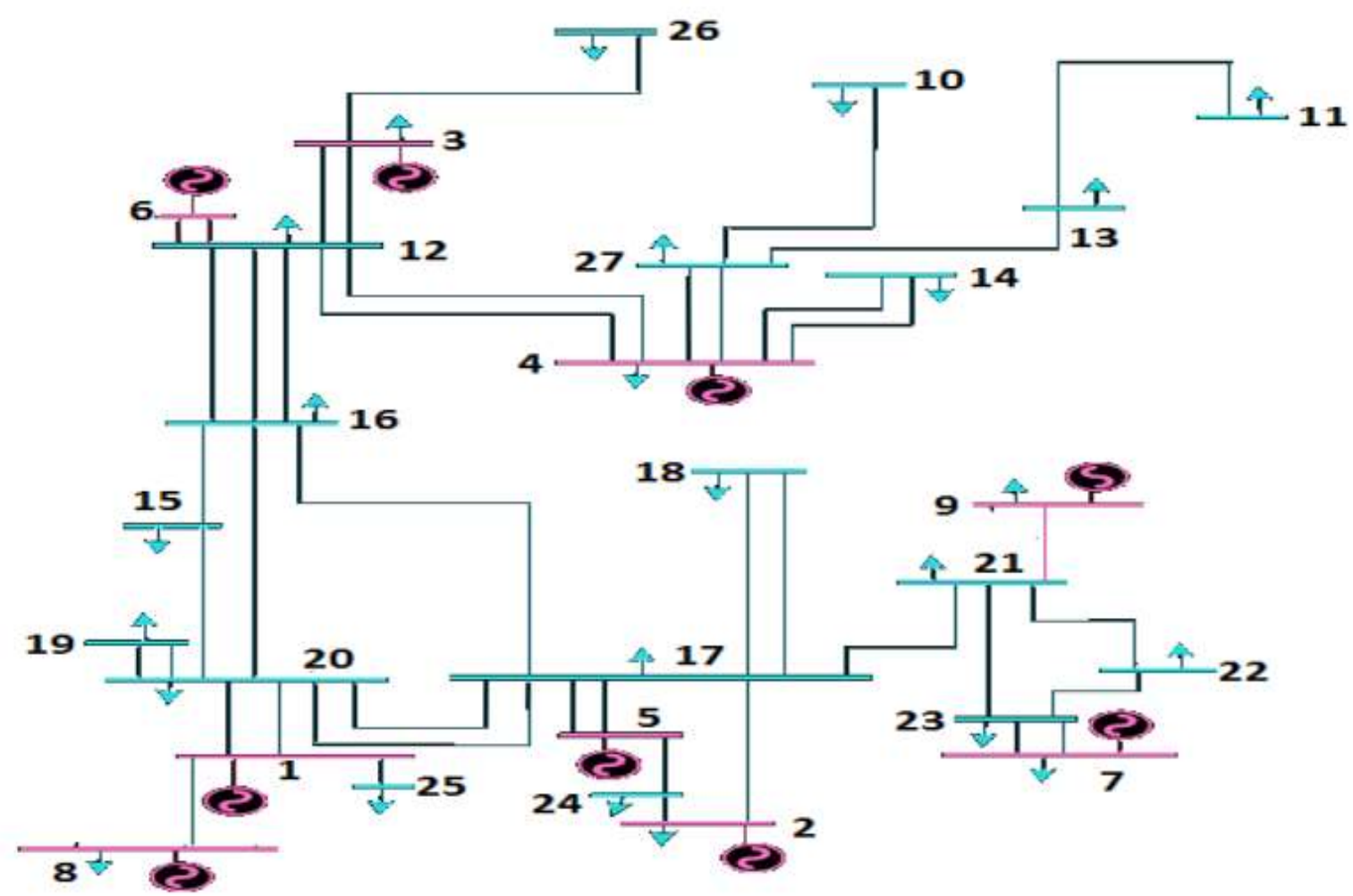

Fig 1: Single line diagram of Nigeria 330kV Power system network (Source: [5])

Table 1: Bus Description of Nigeria 330kV Transmission System Network

\begin{tabular}{llll}
\hline Bus Num & Bus Name/Rating (MVA/MW) & Bus Number & Bus Name/Rating (MVA) \\
\hline 1 & Egbin (+880MW) & 2 & Delta (+300MW) \\
3 & Kainji $(+400 \mathrm{MW})$ & 4 & Shiroro $(+600 \mathrm{MW})$ \\
5 & Sapele $(90 \mathrm{MW})$ & 6 & Jebba GS $(+300 \mathrm{MW})$ \\
7 & Afam $(+470 \mathrm{MW})$ & 8 & AES $(+300 \mathrm{MW})$ \\
9 & Okapi $(+490 \mathrm{MW})$ & 10 & Kano $(-253-\mathrm{j} 129) \mathrm{MVA}$ \\
11 & Gombe $(-74-\mathrm{j} 38) \mathrm{MVA}$ & 12 & Jebba TS $(-8-\mathrm{j} 4) \mathrm{MVA}$ \\
13 & Jos $(-82-\mathrm{j} 42) \mathrm{MVA}$ & 14 & Katampe $(-200-\mathrm{j} 103) \mathrm{MVA}$ \\
15 & Ayede $(-177-\mathrm{j} 91) \mathrm{MVA}$ & 16 & Oshogbo $(-120-\mathrm{j} 86) \mathrm{MVA}$ \\
17 & Benin $(-161-\mathrm{j} 82) \mathrm{MVA}$ & 18 & Ajaokuta $(-63-\mathrm{j} 32) \mathrm{MVA}$ \\
19 & Akangba $(-233-\mathrm{j} 119) \mathrm{MVA}$ & 20 & IK West $(-334-\mathrm{j} 171) \mathrm{MVA}$ \\
21 & Onitsha $(-131-\mathrm{j} 67) \mathrm{MVA}$ & 22 & N Heaven $(-113-\mathrm{j} 57) \mathrm{MVA}$ \\
23 & Alaoji $(-164-\mathrm{j} 83) \mathrm{MVA}$ & 24 & Aladja $(-48-\mathrm{j} 24) \mathrm{MVA}$ \\
25 & Aja $(-120-\mathrm{j} 62)$ MVA & 26 & Birnin Kebbi $(-70-\mathrm{j} 36) \mathrm{MVA}$ \\
27 & Kaduna $(-150-\mathrm{j} 77) \mathrm{MVA}$ & & \\
\hline
\end{tabular}

Source: $[4,6,7]$ 
Table 2: Power Plants Capacity and Locations in the Network

\begin{tabular}{llll}
\hline S/N & Plant & Location & Avaliable capacity $(\mathrm{mw})$ \\
\hline 1. & Afam combine cycle power plant & Rivers state & 470 \\
2. & Okapi combine cycle power plant & Delta state & 490 \\
3. & Egbin thermal power plant & Lagos state & 880 \\
4. & Sapele thermal power plant & Delta state & 90 \\
5. & ASE thermal power plant & Lagos state & 300 \\
6. & Delta power plant & Delta state & 300 \\
7. & Kainji hydro power plant & Niger state & 400 \\
8. & Jebba hydro power plant & Niger state & 300 \\
9. & Shiroro hydro power plant & Niger state & 600 \\
\hline
\end{tabular}

Source: [4]

Table 3: Line per unit parameter and distance

\begin{tabular}{|c|c|c|c|}
\hline \multicolumn{2}{|c|}{ Bus Number } & \multirow{2}{*}{$\begin{array}{l}\text { Length } \\
(\mathrm{Km})\end{array}$} & \multirow{2}{*}{$\begin{array}{l}\text { Per unit Impedance } \\
\qquad(\Omega / \mathrm{Km})\end{array}$} \\
\hline From & To & & \\
\hline 19 & 20 & 17 & $0.0006+j 0.0051$ \\
\hline 15 & 16 & 115 & $0.0041+j 0.0349$ \\
\hline 20 & 1 & 62 & $0.0022+j 0.0172$ \\
\hline 20 & 17 & 280 & $0.0101+j 0.0799$ \\
\hline 16 & 12 & 249 & $0.0056+j 0.477$ \\
\hline 16 & 17 & 251 & $0.0089+j 0.0763$ \\
\hline 12 & 6 & 8 & $0.003+j 0.0022$ \\
\hline 12 & 4 & 244 & $0.0087+j 0.0742$ \\
\hline 12 & 3 & 81 & $0.0022+j 0.0246$ \\
\hline 3 & 26 & 310 & $0.0111+j 0.0942$ \\
\hline 4 & 14 & 87 & $0.0034+j 0.0292$ \\
\hline 27 & 10 & 320 & $0.0082+j 0.0899$ \\
\hline 13 & 11 & 265 & $0.0095+j 0.081$ \\
\hline 17 & 18 & 195 & $0.007+j 0.056$ \\
\hline 17 & 21 & 137 & $0.0049+j 0.0416$ \\
\hline 17 & 5 & 50 & $0.0018+j 0.0139$ \\
\hline 21 & 22 & 96 & $0.0034+j 0.0292$ \\
\hline 21 & 23 & 138 & $0.0049+j 0.0419$ \\
\hline 23 & 7 & 25 & $0.009+j 0.007$ \\
\hline 5 & 24 & 63 & $0.0023+j 0.019$ \\
\hline 2 & 24 & 30 & $0.0011+j 0.0088$ \\
\hline 3 & 12 & 81 & $0.0022+j 0.0246$ \\
\hline 15 & 20 & 137 & $0.0049+j 0.0416$ \\
\hline 1 & 25 & 28 & $0.0022+j 0.0172$ \\
\hline 27 & 13 & 197 & $0.007+j 0.0599$ \\
\hline 13 & 14 & 275 & $0.0029+j 0.0246$ \\
\hline 16 & 20 & 252 & $0.0049+j 0.0341$ \\
\hline 17 & 2 & 107 & $0.0022+j 0.019$ \\
\hline 21 & 9 & 80 & $0.009+j 0.007$ \\
\hline 14 & 18 & 28 & $0.0022+j 0.0172$ \\
\hline 4 & 27 & 96 & $0.0034+j 0.0292$ \\
\hline 1 & 8 & 31 & $0.0041+j 0.0162$ \\
\hline 22 & 23 & 145 & $0.0051+j 0.031$ \\
\hline
\end{tabular}

\section{COMPUTATION OF BALANCED FAULT}

For a balance fault occurring at any point " $\mathrm{x}$ " measured from the sending end in an unloaded line is given by

$$
I_{s c f}=\frac{V_{p f}}{Z_{t h}} \times I_{B}
$$

where $I_{s c f}$ is short circuit fault current; $V_{p f}$ is the per unit pre-fault voltage at the point of fault; $Z_{t h}$ is the per unit effective impedance of the system when viewed from the point of fault and $I_{B}$ is the common base current.

For this system with many generators, the effective fault current, $I_{\text {eff }}$ occurring at any point in the network will be the phasor sum of the individual generator's contribution to the fault current and the load current [6].

$$
I_{e f f}=\sum_{i=1}^{9} I_{G i}^{L}+\sum_{i=1}^{9} I_{g f c i}
$$

Where $\sum_{i=1}^{9} I_{G i}^{L}$ is the sum of all the generators contribution to the load current at the location under analysis; $\sum_{i=1}^{9} I_{g f c i}$ is the sum of all the generation's contribution to the fault current at the point of fault under analysis.

The effect of the fault current $I_{f}$ on different parts of the circuits is calculated by using current divider rule. The voltage at different parts of the network during the fault can also be calculated by the voltage divider rule

\section{COMPUTATION OF UNBALANCED FAULT}

Computation and analysis of unbalanced faults are very difficult task, symmetrical components which yields three (mocked) single phase networks, with only one of which containing the driving e.m.f are employed. As the system reactance is balanced, the three mocked networks have no mutual coupling between them; as such, the unbalanced fault system is made a balanced system by the symmetrical 
components; after the analysis of the mocked balance system has been made; the result is then transferred back to the unbalanced state. This makes the analysis of such unbalanced faults easy.

\section{SYSTEM ANALYSIS}

Fault analysis of the Nigeria $330 \mathrm{kV}$ transmission system will be analyzed in this section. Because of the complexity of the system, the analysis is to be done by using ETAP simulation.

In running the fault analysis, we shall make the following assumptions

(i) All load is in service and

(ii) The fault occurred at a pre-fault voltage which is equal to the rated voltage of $330 \mathrm{kV}$

(iii) Each fault occurred discretely.

Since the network is quite large, this paper only focused and covered all the probable points of fault occurrences; hence, locations of fault occurrence shall be selected at random. Areas covered are buses 4, 16 and 23.

\section{ANALYSIS OF BALANCE FAULT AT BUS 4}

The results of the three phase (balanced) fault occurring in bus 4 are presented in the Tables 4 .
Table 4: Results of 3-Phase Fault at bus 4

\begin{tabular}{|c|c|c|c|}
\hline \multicolumn{2}{|c|}{ Contribution } & \multirow{2}{*}{$\begin{array}{l}\% \text { Vol } \\
\text { from Bus }\end{array}$} & \multirow[t]{2}{*}{ Current (kA) } \\
\hline From & To & & \\
\hline 12 & 4 & 77.1 & 1.515 \\
\hline 14 & 4 & 0.00 & 0.00 \\
\hline 27 & 4 & 0.00 & 0.00 \\
\hline Shiroro & 4 & 100 & 6.419 \\
\hline \multicolumn{2}{|c|}{ Effective Total } & 0.00 & $8.006<-86.8$ \\
\hline
\end{tabular}

\section{DISCUSSION OF RESULTS OF BALANCE FAULTS AT BUS 4}

For balance faults occurring at bus 4 , the northern Nigeria are mainly affected with faults on this bus with buses 10,11, 13, 14 and 27 are cut off from service from the network. Other northern region buses have voltages less than $280 \mathrm{kV}$. However, from Oshogbo to Ajaokuta down to the southern region of Nigeria, the buses are less or not affected as all buses have voltages of $310 \mathrm{kV}$ and above. The faulty bus 4 has a resultant magnitude of $0.0 \%$ of rated $330 \mathrm{kV}$ and $8.01 \mathrm{kA}$. A cross section of the network for a 3 phase fault is shown in Appendix 1 .

\section{ANALYSIS OF UNBALANCE FAULT AT BUS 4}

The results of unbalance fault occurring in bus 4 are presented in the Tables 5, 6 and 7 for line to line, single line to ground and double line to ground faults respectively.

Table 5: Results of LL Fault at bus 4

\begin{tabular}{lccccccc}
\hline \multicolumn{2}{c}{ Contribution } & \multicolumn{2}{c}{ \% Voltage at From Bus } & \multicolumn{2}{c}{ Current at From Bus (kA) } \\
\hline From & To & $V_{a}$ & $V_{b}$ & $V_{c}$ & $I_{a}$ & $I_{b}$ & $I_{c}$ \\
\hline 12 & 4 & $99.3 \angle-0.5$ & $83.4 \angle-126.4$ & $84.23 \angle 126.2$ & $0.04 \angle-36.2$ & $1.332 \angle-176.6$ & $1.301 \angle 4.5$ \\
14 & 4 & $97.96 \angle-1.4$ & $48.98 \angle 178.6$ & $48.98 \angle 178.6$ & $0.0 \angle 0$ & $00.0 \angle 0$ & $0.0 \angle 0$ \\
27 & 4 & $97.96 \angle-1.4$ & $48.98 \angle 178.6$ & $48.98 \angle 178.6$ & $0.0 \angle 0$ & $00.0 \angle 0$ & $0.0<0$ \\
Shiroro & 4 & $100 \angle 0$ & $100 \angle-120$ & $100 \angle 120$ & $0.04 \angle 143.8$ & $5.747 \angle-175.2$ & $5.777 \angle 4.5$ \\
\hline \multicolumn{2}{c}{ Total } & $97.96 \angle-1.4$ & $48.98 \angle 178.6$ & $48.98 \angle 178.6$ & $0.0 \angle 0$ & $7.079 \angle-175.5$ & $7.079 \angle 4.5$ \\
\hline
\end{tabular}

Table 6: Results of $L G$ Fault at bus 4

\begin{tabular}{lccccccc}
\hline \multicolumn{2}{l}{ Contribution } & \multicolumn{2}{c}{ \% Voltage at From Bus } & \multicolumn{2}{c}{ Current at From Bus (kA) } \\
\hline From & To & $V_{a}$ & $V_{b}$ & $V_{c}$ & $I_{a}$ & $I_{b}$ & $I_{c}$ \\
\hline 12 & 4 & $80.90<0$ & $96.05 \angle-116.5$ & $95.72 \angle 115.8$ & $1.321 \angle-85.4$ & $0.515 \angle 96.8$ & $0.558 \angle 92.8$ \\
14 & 4 & $0.0 \angle 0$ & $88.82 \angle-109.5$ & $90.4 \angle 106.8$ & $00.0 \angle 0$ & $00.0 \angle 0$ & $00.0 \angle 0$ \\
27 & 4 & $0.0 \angle 0$ & $88.82 \angle-109.5$ & $90.43 \angle 106.8$ & $00.0 \angle 0$ & $00.0 \angle 0$ & $00.0 \angle 0$ \\
Shiroro 4 & $100 \angle 0$ & $100 \angle-120$ & $100 \angle 120$ & $8.665 \angle-84.7$ & $0.515 \angle-83.2$ & $0.558 \angle-87.2$ \\
\hline \multicolumn{2}{r}{ Resultant } & $0.0 \angle 0$ & $88.82 \angle-109.5$ & $90.43 \angle 106.8$ & $9.986 \angle-84.8$ & $00.0 \angle 0$ & $00.0 \angle 0$ \\
\hline
\end{tabular}

Table 7: Results of LLG Fault at bus 4

\begin{tabular}{lccccccc}
\hline \multicolumn{2}{c}{ Contribution } & \multicolumn{2}{c}{$\%$ Voltage at from Bus } & \multicolumn{3}{c}{ Current at from Bus (kA) } \\
\hline From & To & $V_{a}$ & $V_{b}$ & $V_{c}$ & $I_{a}$ & $I_{b}$ & $I_{c}$ \\
\hline 12 & 4 & $89.46 \angle-0.6$ & $79.45 \angle-122.4$ & $79.96 \angle 122.1$ & $0.702 \angle-83.2$ & $1.425 \angle 163.0$ & $1.392 \angle 25.2$ \\
14 & 4 & $70.14 \angle-3.3$ & $0.0 \angle 0$ & $0.0 \angle 0$ & $0.0 \angle 0$ & $0.0 \angle 0$ & $0.0 \angle 0$ \\
27 & 4 & $70.14 \angle-3.3$ & $0.0 \angle 0$ & $0.0 \angle 0$ & $0.0 \angle 0$ & $0.0 \angle 0$ & $0.0 \angle 0$ \\
Shiroro & 4 & $100 \angle 0$ & $100 \angle-120$ & $100 \angle 120$ & $0.702 \angle 96.8$ & $8.175 \angle 138.8$ & $8.039 \angle 49.7$ \\
\multicolumn{2}{l}{ Resultant } & $70.14 \angle-3.3$ & $0.0 \angle 0$ & $0.0 \angle 0$ & $0.0 \angle 0$ & $9.493 \angle 142.4$ & $9.324 \angle 46.1$ \\
\hline
\end{tabular}




\section{DISCUSSION OF RESULTS OF UNBALANCE FAULTS AT BUS 4}

For unbalanced faults at the bus, the complete network is highly affected as all buses apart from 10, $11,13,14$ and 27 (that do not have supply) are running on voltages less than 200kV. Bus 4 resultant yellow and blue line voltages dipped to as low as $49 \%$ rated voltage for LL fault. For unbalance fault, bus 4 resultant magnitudes are $169.9 \mathrm{kV}$ and $9.99 \mathrm{kA}$, $186.64 \mathrm{kV}$ and $0.0 \mathrm{kA}, 133.64 \mathrm{kV}$ and $12.56 \mathrm{kA}$ for LG, LL and LLG faults at the bus respectively.

\section{ANALYSIS OF BALANCE FAULTS AT BUS 23}

The result of 3-phase (balance) faults occurring in bus 23 is presented in the Table 8 .

Table 8: Results of 3 Phase Fault at Bus 23

\begin{tabular}{cccc}
\hline \multicolumn{2}{c}{ Contribution } & $\begin{array}{c}\% \text { Vol } \\
\text { from Bus }\end{array}$ & Current (kA) \\
\hline \multicolumn{2}{c}{ From } & To & \\
\hline 7 & 23 & 21.09 & 4.013 \\
21 & 23 & 46.73 & 1.611 \\
22 & 23 & 28.12 & 0.922 \\
\hline \multicolumn{2}{c}{ Resultant } & 0.00 & $6.546 \angle-86.6$ \\
\hline
\end{tabular}

\section{DISCUSSION OF RESULTS OF BALANCE FAULTS AT BUS 23}

For faults at bus 23, the system/network is less affected when the fault is a balanced one with buses $7,21,22$ and 23 most affected. The simulation in
ETAP shows that most of the buses have voltage of magnitude up to $320 \mathrm{kV}$. For a balanced fault, bus 23 resultant magnitudes are $0 \%$ of rated voltage and $6.55 \mathrm{kA}$.

\section{ANALYSIS OF UNBALANCE FAULT AT BUS 23}

The results of unbalance fault occurring in bus 23 are presented in the Tables 9, 10 and 11 for line to line, single line to ground and double line to ground faults respectively.

\section{DISCUSSION OF RESULTS OF UNBALANCE FAULTS AT BUS 23}

The unbalanced faults occurring at bus 23 greatly affect the network; for LL and LG faults, no bus in the network had voltage of magnitude up to $200 \mathrm{kV}$; the highest recorded voltage magnitude for a LLG fault was $213 \mathrm{kV}$. For unbalanced fault, the bus resultant magnitudes are $204 \mathrm{kV}$ and $5.6 \mathrm{kA} ; 187.92 \mathrm{kV}$ and $0.0 \mathrm{kA} ; 213.5 \mathrm{kV}$ and $4.77 \mathrm{kA}$ for $L G$, LL and LLG faults respectively.

A cross section of the network for a LL fault at bus 23 is shown in Appendix 2.

\section{ANALYSIS OF BALANCE FAULTS AT BUS $\mathbf{1 6}$}

The results of balance fault occurring in bus 16 are presented in the Tables 12.

Table 9: Results of LL Fault at bus 23

\begin{tabular}{|c|c|c|c|c|c|c|c|}
\hline \multicolumn{2}{|c|}{ Contribution } & \multicolumn{3}{|c|}{$\%$ Voltage at from Bus } & \multicolumn{3}{|c|}{ Current at from Bus (kA) } \\
\hline From & To & $V_{a}$ & $V_{b}$ & $V_{c}$ & $I_{a}$ & $I_{b}$ & $I_{c}$ \\
\hline 7 & 23 & $8.52<-1.0$ & $52.16<-160.1$ & $53.16<1$ & $0.035<143.8$ & $3.530<-1$ & $3.530<4.3$ \\
\hline 21 & 23 & $99.04<-0.6$ & $63.64 \angle-140.9$ & $64.52 \angle 140.3$ & $0.022<-36.2$ & $1.411<-176.3$ & $1.393 \angle 4.3$ \\
\hline 22 & 23 & $98.88<-0.8$ & $54.81<-154.3$ & $55.51<153.1$ & $0.013<-36.2$ & $0.808<-176.3$ & $0.798 \angle 4.3$ \\
\hline Resu & & $98.63<-0.9$ & $49.32 \angle 179.1$ & $49.32 \angle 179.1$ & $0.0<0$ & $5.748<-175.7$ & $5.748 \angle 4.3$ \\
\hline
\end{tabular}

Table 10: Results of $L G$ Fault at bus 23

\begin{tabular}{|c|c|c|c|c|c|c|c|}
\hline \multicolumn{2}{|c|}{ Contribution } & \multicolumn{3}{|c|}{$\%$ Voltage at from Bus } & \multicolumn{3}{|c|}{ Current at from Bus (kA) } \\
\hline From & To & $V_{a}$ & $V_{b}$ & $V_{c}$ & $I_{a}$ & $I_{b}$ & $I_{C}$ \\
\hline 7 & 23 & $44.78<-0.5$ & $93.89<-115.2$ & $94.83<113.7$ & $3.821<-84.3$ & $0.359<-83.0$ & $0.385 \angle-86.4$ \\
\hline 21 & 23 & $52.29<-0.1$ & $100.74 \angle-122.1$ & $101.56<121.1$ & $1.128<-84.7$ & $0.228<97.0$ & $0.245 \angle 93.6$ \\
\hline 22 & 23 & $31.46<-0.1$ & $103.17<-124.7$ & $104.49 \angle 123.3$ & $0.646<-84.7$ & $0.131<97.0$ & $0.140<93.6$ \\
\hline $\mathrm{Re}$ & & $0.0<0$ & $107.22<-128.3$ & $109.20<126.5$ & $5.595<-84.4$ & $0.0<0$ & $0.0<0$ \\
\hline
\end{tabular}

Table 11: Results of LLG Fault at bus 23

\begin{tabular}{lcrccccc}
\hline \multicolumn{2}{l}{ Contribution } & \multicolumn{2}{c}{ \% Voltage at from Bus } & \multicolumn{2}{c}{ Current at from Bus (kA) } \\
\hline \multicolumn{2}{r}{ From } & \multicolumn{1}{l}{$V_{a}$} & $V_{b}$ & $V_{c}$ & $I_{a}$ & $I_{b}$ & $I_{c}$ \\
\hline 7 & 23 & $89.21 \angle-1.6$ & $35.18 \angle-149.4$ & $36.01 \angle 147.8$ & $0.341 \angle 99.6$ & $3.978 \angle 157.7$ & $3.919 \angle 31.1$ \\
21 & 23 & $101.61 \angle-1.0$ & $49.07 \angle-124.6$ & $49.50 \angle 124.4$ & $0.217 \angle-80.4$ & $1.470 \angle 168.7$ & $1.436 \angle 19.6$ \\
22 & 23 & $105.77 \angle-1.3$ & $29.52 \angle-124.6$ & $29.78 \angle 124.4$ & $0.124 \angle-80.4$ & $0.842 \angle 168.7$ & $0.822 \angle 19.6$ \\
\hline \multicolumn{2}{l}{ Resultant } & $112.06 \angle-1.6$ & $0.0 \angle 0$ & $0.0 \angle 0$ & $0.0 \angle 0$ & $6.262 \angle 161.7$ & $6.148 \angle 26.9$ \\
\hline
\end{tabular}


Table 12: Results of 3 Phase Fault at Bus 16

\begin{tabular}{|c|c|c|c|}
\hline \multicolumn{2}{|c|}{ Contribution } & \multirow[t]{2}{*}{$\%$ Vol from Bus } & \multirow[t]{2}{*}{ Current (kA) } \\
\hline From & To & & \\
\hline 12 & 16 & 78.72 & 1.504 \\
\hline 15 & 16 & 26.20 & 1.084 \\
\hline 17 & 16 & 66.93 & 1.269 \\
\hline 20 & 16 & 57.41 & 1.084 \\
\hline \multicolumn{2}{|c|}{ Resultant } & 0.00 & $4.94 \angle-86.3$ \\
\hline
\end{tabular}

\section{DISCUSSION OF RESULTS OF BALANCE FAULTS AT BUS 16}

The effect of balanced fault on bus 16 is fair on the network as the least recorded voltage was over $230 \mathrm{kV}$; however, the north-east and few buses in the south-east are lightly affected as their bus voltages were over $305 \mathrm{kV}$. A 3 - $\varnothing$ fault gives a bus resultant of $0.0 \mathrm{kV}$ and $4.94 \mathrm{kA}$

\section{ANALYSIS OF UNBALANCE FAULT AT BUS 16}

The results of unbalance fault occurring in bus 16 are presented in the Tables 13, 14 and 15 for line to line, single line to ground and double line to ground faults respectively.

\section{DISCUSSION OF RESULTS OF UNBALANCE FAULTS AT BUS 16}

For unbalance fault at bus 16 , the recorded bus 16 voltage and current was $248.93 \mathrm{kV}$ and $1.87 \mathrm{kA}$; $189.85 \mathrm{kV}$ and $0 \mathrm{kA} ; 242.85 \mathrm{kV}$ and $2.72 \mathrm{kA}$ for LLG, LL and LG (double line to ground, line to line and line to ground) faults respectively.

A cross section of the network for a LL fault is shown in Appendix 3.

\section{CONCLUSION}

Faults occurring in the $330 \mathrm{kV}$ Nigeria transmission system cause the network to behave differently when they occur at different locations which depend on the type of the faults. The 3 locations investigated in this paper show that the network is mostly affected by unbalanced faults. The buses directly connected to the faulted bus are the most affected as they directly contribute to the fault bus current and voltage. The resulted bus line parameters are the vector sum of the phase contributions of the buses directly connected to the faulty bus.

Table 13: Results of LL Fault at bus 16

\begin{tabular}{|c|c|c|c|c|c|c|c|}
\hline \multicolumn{2}{|c|}{ Contribution } & \multicolumn{3}{|c|}{$\%$ Voltage at from Bus } & \multicolumn{3}{|c|}{ Current at from Bus (kA) } \\
\hline From & To & $\overline{V_{a}}$ & $V_{b}$ & $V_{c}$ & $I_{a}$ & $I_{b}$ & $I_{c}$ \\
\hline 12 & 16 & $99.65<-0.2$ & $84.39<-126.1$ & $84.87 \angle 126.1$ & $0.0<-40.6$ & $1.307 \angle-176.0$ & $1.307 \angle 4.0$ \\
\hline 15 & 16 & $54 \angle 0.2$ & 54 & $54.91 \angle 1$ & 141.9 & 6.0 & 4.0 \\
\hline 17 & 16 & & & $0<1$ & $0.001<-37.3$ & 5.0 & $1.102 \angle 4.0$ \\
\hline 20 & 4 & $63 \angle 0.2$ & $70.30<$ & $70.74 \angle 1$ & $0<12$ & $0.942 \angle$ & $0.942 \angle 4.0$ \\
\hline \multicolumn{2}{|c|}{ Resultant } & $99.65<-0.2$ & $49.82 \angle 179.8$ & $49.82 \angle 179.8$ & $0.0<0$ & $4.294 \angle-176.0$ & $4.294 \angle 4.0$ \\
\hline
\end{tabular}

Table 14: Results of $L G$ Fault at bus 16

\begin{tabular}{|c|c|c|c|c|c|c|c|}
\hline \multicolumn{2}{|c|}{ Contribution } & \multicolumn{3}{|c|}{$\%$ Voltage at from Bus } & \multicolumn{3}{|c|}{ Current at from Bus (kA) } \\
\hline From & To & $V_{a}$ & $V_{b}$ & $V_{c}$ & $I_{a}$ & $I_{b}$ & $I_{c}$ \\
\hline 12 & 16 & $88.45 \angle-0.1$ & $99.80<-120.2$ & $100.04 \angle 119.9$ & $0.831<-84.1$ & $0.002<-84.7$ & $0.002<-82.8$ \\
\hline 15 & 16 & $29.14 \angle-0.1$ & $117.26<-133.4$ & $118.96<132.4$ & $0.596<84.1$ & $0.002 \angle 95.0$ & $0.001<100.6$ \\
\hline 17 & 16 & $75.02<-0.1$ & $103.25<-123.6$ & $103.89<123.2$ & $0.700 \angle 84.1$ & $0.001<-85.4$ & $0.001<-71.5$ \\
\hline 20 & 4 & $63.86<-0.1$ & $106.49 \angle$ & $107.39<125.8$ & $0.596 \angle 84.1$ & 0.002 & $0.001 \angle 100.6$ \\
\hline $\mathrm{Re}$ & & $0.0 \angle 0$ & $127.46<-138.4$ & $129.72 \angle 137.1$ & $2.721<-84.1$ & $0.0 \angle 0$ & $0.0 \angle 0$ \\
\hline
\end{tabular}

Table 15: Results of LLG Fault at bus 16

\begin{tabular}{lcrccccc}
\hline \multicolumn{2}{c}{ Contribution } & \multicolumn{2}{c}{ \% Voltage at from Bus } & \multicolumn{3}{c}{ Current at from Bus (kA) } \\
\hline From & To & $V_{a}$ & $V_{b}$ & $V_{c}$ & $I_{a}$ & $I_{b}$ & $I_{c}$ \\
12 & 16 & $99.67 \angle-0.3$ & $82.12 \angle-123.9$ & $82.55 \angle 123.8$ & $0.001 \angle 92.0$ & $1.349 \angle 171.7$ & $1.326 \angle 16.4$ \\
15 & 16 & $120.54 \angle-0.5$ & $27.22 \angle-123.5$ & $27.37 \angle 123.5$ & $0.001 \angle-98.0$ & $0.972 \angle 171.9$ & $0.955 \angle 16.3$ \\
17 & 16 & $104.45 \angle-0.4$ & $69.76<-123.8$ & $70.09 \angle 123.8$ & $0.000 \angle 51.2$ & $1.138 \angle 171.7$ & $1.118 \angle 16.4$ \\
20 & 4 & $108.49 \angle-0.4$ & $59.64 \angle-123.5$ & $59.97 \angle 123.5$ & $0.001 \angle-98.0$ & $0.972 \angle 171.9$ & $0.955 \angle 16.3$ \\
\hline \multicolumn{2}{r}{ Resultant } & $130.65 \angle-0.6$ & $0.0 \angle 0$ & $0.0 \angle 0$ & $0.0 \angle 0$ & $4.431 \angle 171.8$ & $4.354 \angle 16.3$ \\
\hline
\end{tabular}


The results also shows that LLG (between line "a" and " $b$ ") fault at bus 23 produces a $0.0 \%$ voltage in the 2 affected lines but a high voltage of $112 \%$ of rated line voltage at the last line at the faulty bus 23 . This same LLG fault at bus 16 produces similar results but a higher last phase voltage of $131 \%$ of rated line voltage in the faulty bus 16 . LL faults always result reduction in voltage of the two lines under fault. In bus 23 , the phase voltages of the affected lines were $49.32 \%$ of the rated line voltage. Note that the resultant current and voltage values were as a result of the various responses to the fault by all the power plants (and buses) in the network and converge at the faulted bus through the buses linking it. For example, the resultant voltage and current values of bus 16 are the sum of the contribution of buses $12,15,17$ and 20 to the fault of bus 16 .

With a good understanding of the behavior of the network when different faults occur, planning the network protection can be made easy, effective and cheaper.

\section{REFERENCES}

[1] D. Tziouvaras "Analysis of Complex Power System Faults and Operating Conditions" $63^{\text {rd }}$ Annual Georgia Tech Protective Relaying Conference, pp 1 - 16, 2009.
[2] S. J. Mabeta "Open conductor faults and dynamic analysis of an electric power system" M.Sc Thesis in Electrical Engineering, Norwegian University of Science and Technology, 2011.

[3] J. Iżykowski, "Power System Faults" Avaliable at www.printpap.pl, 2011.

[4] U. C Ogbuefi and T. C. Madueme, "A Power Flow Analysis of the Nigerian $330 \mathrm{KV}$ Electric Power System" IOSR Journal of Electrical and Electronic Engineering (IOSR-JEEE), Vol. 10, Iss. 1 Ver. 1, pp $46-57,2015$.

[5] F. I. Izuegbunam, C. B. Ubah and I. O. Akwukwaegbu, "Dynamic security Assessment of $330 \mathrm{kv}$ Nigeria Power System" Academic Research international, Vol. 3, No. 1, pp 456 466, 2012.

[6] PHCN National Control Centre Oshogbo, "Generation and Transmission Grid Operations". Annual Technical Report for 2005. PHCN publisher, 2006.

[7] PHCN National Control Centre Oshogbo Daily Operational report, May 2012.

[8] B. R. Gupta, "Power System Analysis and Design" S. Chand and Company Limited. Ram Nagar, New Delhi, 2005. 
Appendix 1: Cross section of Nigeria 330kV transmission network for a fault at bus 4.

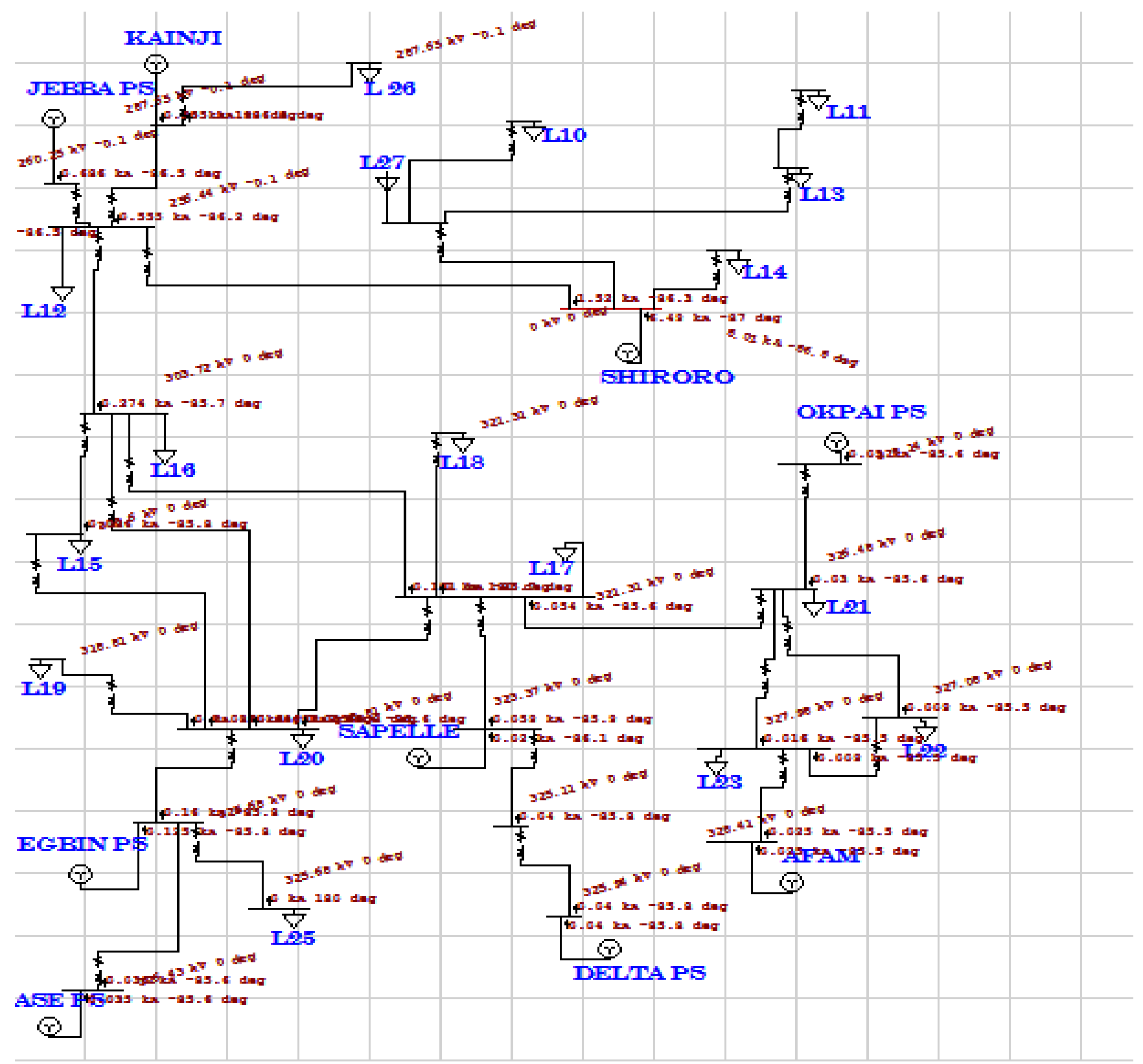


Appendix 2: Cross section of Nigeria 330kV transmission network for a LLG Fault at bus 23

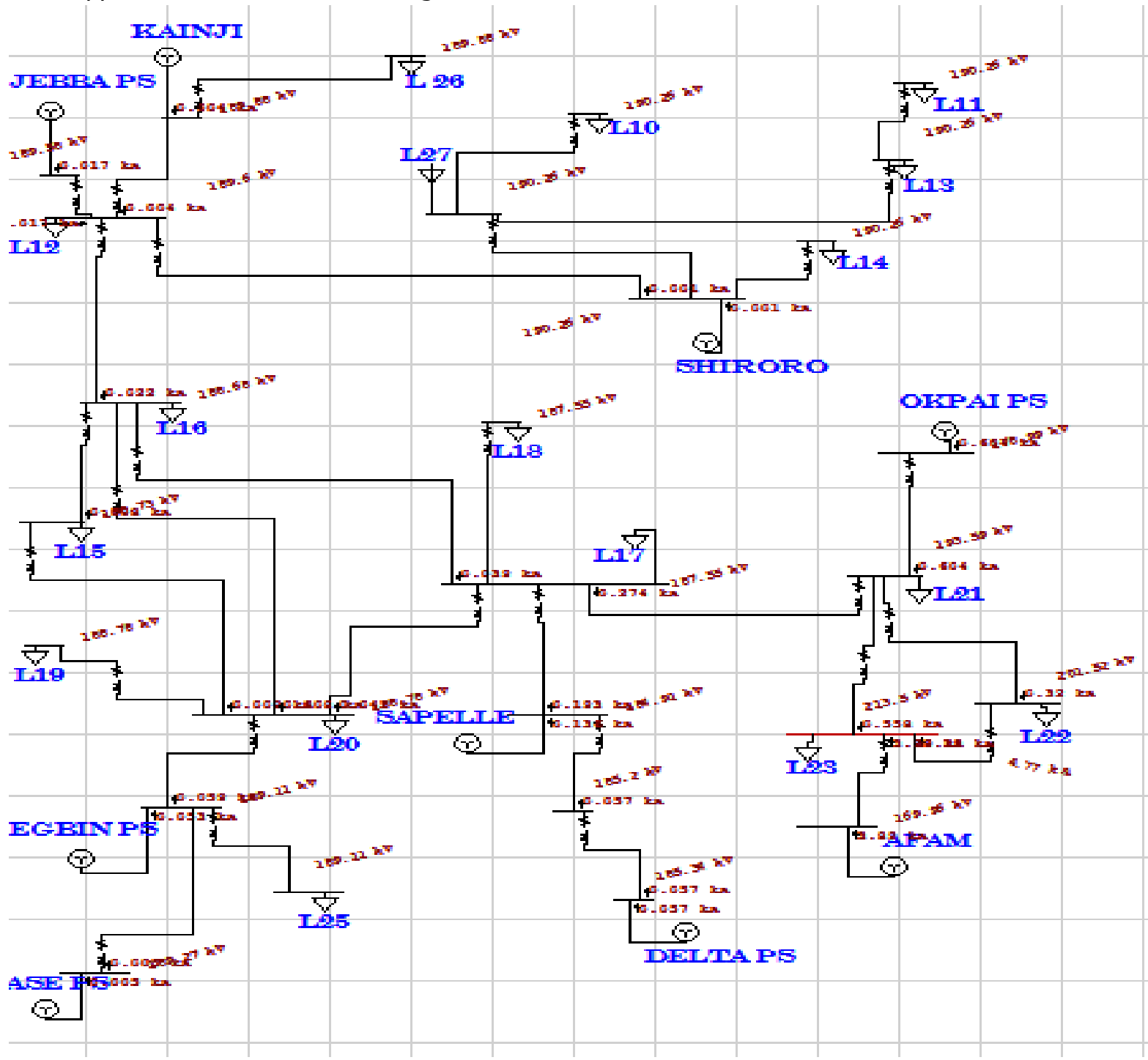


Appendix 3: Cross section of Nigeria 330kV transmission network for a LL Fault at bus 16

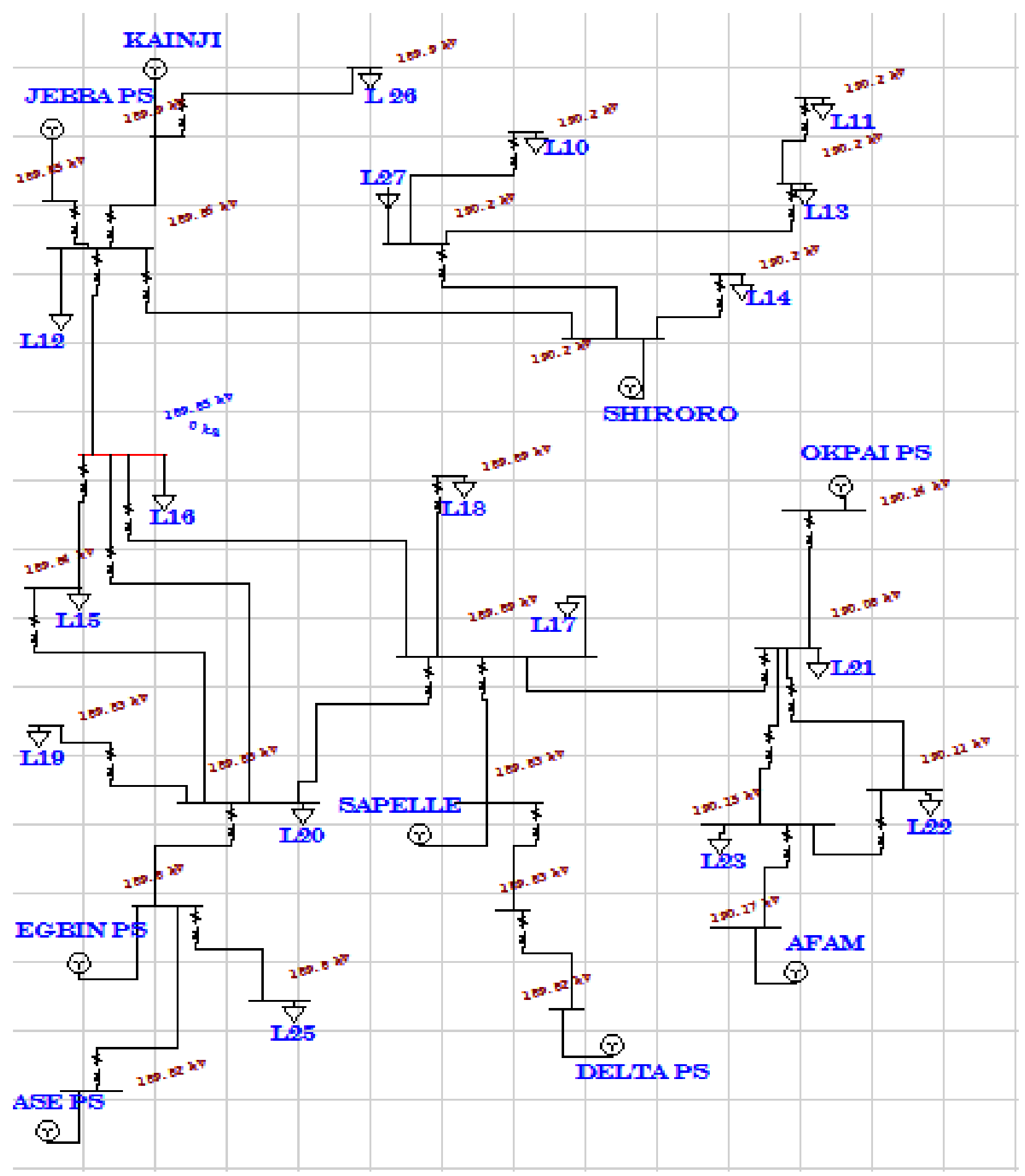

